\title{
Contingency Power for Small Turboshaft Engines Using Water Injection into Turbine Cooling Air
}

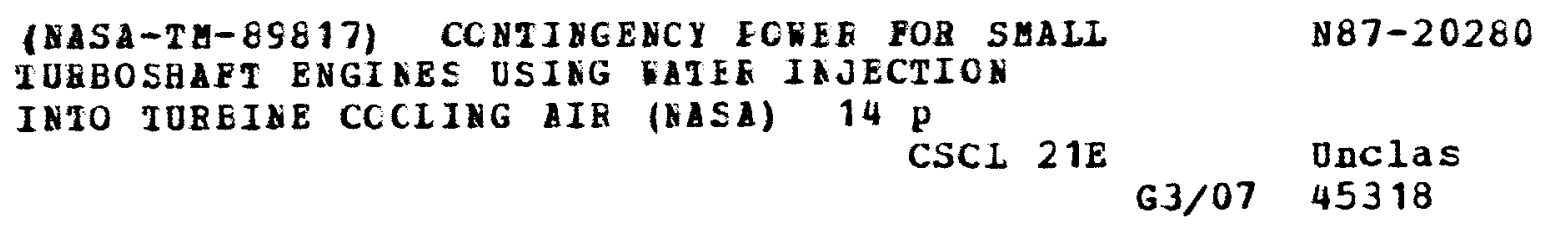

Thomas J. Biesiadny

Lewis Research Center

Cleveland, Ohio

Gary A. Klann and David A. Clark

Propulsion Directorate

U.S. Army Aviation Research and Technology Activity-AVSCOM

Lewis Research Center

Cleveland, Ohio

and

Brett Berger

Lewis Research Center

Cleveland, Ohio

Prepared for the

23rd Joint Propulsion Conference

cosponsored by the AIAA, ASEE, ASME, and SAE

San Diego, California, June 29-July 2, 1987 
CONTINGENCY POWER FOR SMALL TURBOSHAFT ENGINES USING WATER INJECTION INTO TURBINE COOLING AIR

Thomas J. Biesiadny*

National Aeronautics and Space Administration

Lewis Research Center

Cleveland, Ohio 44135

Gary A. Klann and David A. Clark

Proputsion Directorate

U.S. Army Aviation Research and Technology Activity - AVSCOM

Lewis Research Center

Cleveland, Ohio 44135

and

Brett Berger

National Aeronautics and Space Administration

Lewis Research Center

Cleveland, Ohio 44135

\section{Abstract}

Because of one-engine-inoperative (OEI) requirements, together with hot-gas reingestion and hot-day, high-altitude takeoff situations, power augmentation for multiengine rotorcraft has always been of critical interest. However, power augmentation using overtemperature at the turbine inlet will shorten turbine life unless a method of limit$\widetilde{O}$ ing thermal and mechanical stresses is found. A $\vec{m}$ possible solution involves allowing the turbine '́ inlet temperature to rise to augment power while injecting water into the turbine cooling air to limit hot-section metal temperatures. An experimental water injection device was installed in an engine and successfully tested. Although concern for unprotected subcomponents in the engine hot section prevented demonstration of the technique's maximum potential, it was still possible to demonstrate increases in power while maintaining nearly constant turbine rotor blade temperature.

\section{Introduction}

Because of one-engine-inoperative (OEI) requirements, together with hot-gas reingestion and hot-day, high-altitude takeoff situations, power augmentation for multiengine rotorcraft has always been of critical interest. According to an earlier study, 1 one method of power augmentation is overspeed and overtemperature at the turbine inlet. However, power augmentation using overtemperature at the turbine inlet will shorten turbine life unless a method of limiting thermal and mechanical stresses is found.

A possible solution of this dilemma ${ }^{2}$ involves allowing the temperature at the turbine inlet to rise to augmented power while injecting water into the turbine cooling air to maintain the hot-section metal temperatures. The latent heat of vaporization of the injected water is used as a heat sink to cool the compressor bleed air used for cooling the hot section. NASA Lewis has conducted a research study into the feasibility of supplementing turbine cooling by water injection during contingency power events on turboshaft engines. This study has included aspects of basic heat transfer ${ }^{3,4}$ and analytical feasibility and design, 5,6

*Member, AIAA. as well as the experimental demonstration that is the subject of this report. The demonstration was made on a T700 GE-701 turboshaft engine as an adjunct to an ongoing Army and NASA Small Turboshaft Engine Program.

Consistent with the available resources, the demonstration was confined to a study of water injection into the compressor bleed air used for cooling the first-stage high pressure turbine blades. These rotor blades were chosen for study because the effect on life and the possible consequences during contingency power use, with significant increases in temperature, would be more severe than for any other component. The studies completed on the engine cycle, heat transfer, and life analysis indicate that the concept is feasible. However, the logistics of carrying water for this technique and the modifications to the engine control for contingency power situations must be addressed before a system can become operational. Such issues are beyond the scope of this report.

The objective of the tests was to demonstrate higher power output of a turboshaft engine while maintaining the turbine blade temperature by injecting water into the turbine cooling air. The results of these tests are presented in terms of the response of augmented power and turbine blade metal temperature to humid-air cooling during engine operation over a range of power settings. The experimental results of these tests are compared with the analytical results of Hirschkron. ${ }^{5}$

\section{Apparatus and Procedure}

Engine

The engine (Fig. 1) used for the investigation was a front-drive, turboshaft engine consisting of an integral particle separator: a five-stage-axialflow, single-stage-centrifugal-flow compressor; a throughflow annular combustor; a two-stage, axialflow gas generator turbine; and a free two-stage, axial-flow power turbine.

\section{Water Injection System}

The water injection hardware consisted of water supply tubing and a water distribution ring installed within the engine combustor midframe 
assembly (Fig. 2). The supply tubing penetrated the engine midframe outer housing through one of two igniter ports. It was then routed around the combustor and under the inner combustor shroud, where it mated with the distribution ring. The 0.250 -in. tubing was enclosed in another $0.375-$ in. tube to the point where it passed under the shroud. The distribution ring was positioned around a bearing housing directly upstream of the turbine cooling air accelerator assembly. Briefly, the accelerator is a device to accelerate and direct axial flow in a tangential direction so as to aid flow distribution into the turbine rotor. The distribution ring, also of 0.250 -in. tubing, contained five equally spaced 0.037-in.-diameter holes positioned in such a way as to direct the water into the accelerator passages and allow it to evaporate in the turbine cooling air.

The water injection supply (Fig. 3) consisted of a pressurized reservoir of distilled water, a high-pressure gaseous nitrogen supply, valves, tubing, and system-monitoring instrumentation.

\section{Engine Instrumentation}

The instrumentation used for the engine test program consisted of both hot-section instrumentation specifically installed for the contingency power tests and the normal complement of instrumentation to monitor engine operation. The hotsection instrumentation consisted of thermocouples and static pressure taps. The thermocouples on the injector tube were positioned to indicate the condition of the water as it progressed from the supply tank to the distribution ring. The thermocouples and static pressure probes upstream and downstream of the accelerator measured the quality of the steam/air mixture and determined the mass flow through the accelerator. The remaining instrumentation on the seals, the turbine nozzles, the turbine shrouds, the nozzle platforms, and the combustor liner assisted in monitoring the condition of the hot section.

\section{Pyrometer}

The most important instrument required for the test was an optical pyrometer. The pyrometer assembly consisted of a photodiode, a lens, and the associated electronics within a water-cooled case. The pyrometer assembly was mounted on a first-stage turbine nozzle segment within the engine midframe and directed at the leading edge of the first-stage turbine blades (Fig. 4). The signal lead and the cooling water supply and return tubing were routed through specially prepared holes in the outer midframe housing.

The pyrometer system output was connected to an oscilloscope for real-time display and photographing and to a wide-band FM tape recorder for subsequent data recording and analysis. Also part of the system was a once-per-revolution speed signal that was recorded as an index marking to identify specific turbine blades.

\section{Model Tests}

Before each engine test a model test of the water injection system was performed to calibrate the accelerator, to verify assumptions made in the conceptual design studies, and to gain operational experience with the system.

Engine Tests

The conditions under which the engine was tested with the turbine cooling water injection system are summarized in Table I. The water injection concept was initially demonstrated at settings below intermediate rated power (IRP). Data were obtained at several water flow rates to validate the measuring system and the metal temperature versus water flow rate predictions before testing above IRP was begun.

The objective of the engine test was to increase the maximum output power by raising the turbine inlet temperature while keeping the bulk temperature of the first-stage turbine rotor blades within limits.

The test procedure followed a conservative approach. A "derated" part-power base setting was selected where no water was injected. Measurements were then systematically made at increasing levels of power while injecting water. By taking fairly small increments in temperature, any unpredicted trends could be observed. Each water flow rate was held for 1 to $2 \mathrm{~min}$. Hot-section temperature $1 \mathrm{im}$ its were established and adhered to as the test progressed.

The baseline data from which exploration at temperatures above IRP was conducted and the guidelines used from Hirschkron ${ }^{5}$ included the following:

(1) Temperature data from the thermocouples described in the section "Instrumentation" were recorded. These data were extrapolated and used as a guide during the subsequent exploration to higher turbine inlet temperatures.

(2) Significant changes in slope versus the extrapolations would warrant further investigation and corrective action, including inspection of hotsection hardware. No significant deviations were seen during the testing.

(3) A number of routine inspections of hotsection hardware would be performed to establish a correlation between the hot-section condition and increased temperature levels above the established baseline. A new baseline would be established each time a hot-section inspection was conducted. No abnormalities were seen during the inspections.

(4) The blade leading-edge temperatures would be measured with the optical pyrometer.

\section{Results and Discussion}

Results of model tests with the water injection system are presented, as well as the resuits of the engine tests. The model results affected the injection configuration chosen for the engine and were used to calibrate the cooling system accelerator.

\section{Model Tests}

The model tests were conducted to determine the water flow that could be effectively added to 
the turbine cooling airflow of the full-scale turboshaft engine. This information was obtained as well as information on the mass flow function for the turbine cooling air system accelerator. This was also an opportunity to gain operational experience with the water supply system before its use with the engine.

The upper limit of water addition was to be determined by plotting the temperature of the $\mathrm{mix}$ ture against the water/air ratio (Fig. 5). The point at which the water had little additional effect was anticipated to be shown by a corresponding change in slope on the aforementioned curve. The cooling effectiveness of the water addition was of significance at least to a water/air ratio of 10 percent. This helped to determine the upper limit of water addition for the engine tests.

The model tests were conducted with both 5 holes and 15 holes in the distribution ring. No significant transient or steady-state differences were noted between these two configurations. The 5-hole configuration was chosen for the engine tests because it resulted in a higher pressure differential in the supply system and thus allowed greater control of the water.

\section{Engine Tests}

The engine test results include a visual inspection report complled after testing was completed and a detailed discussion of the engine data. The test results show the benefits of water injection into the turbine cooling air and include a comparison of engine data with both the model test data and the predicted results from the conceptual design study. 5

Overall engine condition. - A borescope inspection showed no visual signs of hot-section distress. No engine hot-section disassembly was performed nor was it required. Operational limits regarding gas generator and power output shaft speeds and temperature were observed and never exceeded so as to retain as much turbine blade life as possible. This restriction was also imposed because the engine is a testbed intended for future research work.

This is not to insinuate that no risk was involved in the program. Quite the opposite was true. For the maximum power situations the engine electronic control unit (ECU) was locked out. The engine operator was thus required to monitor and limit rotor speed and turbine temperature. Because of the configuration of the facility power absorber controls and since the engine ECU was locked out, the power absorber command signal required manual btasing to control engine power output speed and to reach the higher power levels. The addition of water injection required a third operator who affected the operating level of the engine. Considering these test variables, a key factor in the successful completion of the testing was the support personnels' expertise.

No atypical vibrations were observed during the testing nor was a compressor stall indicated. The system used for stall detection was proven to be reliable in previous engine tests. The pyrometer performed flawlessly for the duration of the tests, approximately 26 hours, and served well its intended purpose as the primary data source.

Transient system response. - A consideration during the design and planning stage of the program was the state of the water/steam through the injection system. Too much water downstream of the turbine cooling system accelerator (Fig. 4) could conceivably result in "flooding" and sudden cooling of components such as seals. Too little water and the first-stage turbine blades would not be cooled enough to allow for higher turbine inlet temperatures as fuel was added. A maldistribution of the coolant might lead to temperature nonuniformities in the seals downstream of the accelerator and eventual turbine distress. The time to charge the system, or the time to reach a steady-state condition, before the turbine temperature could be increased was also a consideration.

The concerns about flooding, insufficient cooling, and maldistribution of flow were minimized mainly by the test techniques employed and the hardware developed for the program. Regarding the transient response of the system, for a typical water/air ratio of approximately 6 percent, approximately $5 \mathrm{sec}$ elapsed from the time water flow was begun until a change in temperature was observed at a thermocouple measuring metal temperature near the distribution ring. Furthermore, a significant drop in temperature did not occur until about $3 \mathrm{sec}$ later. It should be noted that the time differential between water addition and temperature drop must be taken into account in an operational system. The thermocouples downstream of the accelerator, where the air/steam mixture should be most completely mixed, showed a greater delay.

Steady-state results. - Water was added to the turbine cooling air as described in the section "Apparatus and Procedure." With this water addition the rotor speed (Fig. 6) decreased as did horsepower output ( $\mathrm{Fig} .7$ ). These figures show that adding water in itself did not necessarlly result in a net gain in engine performance. In fact, just the opposite effect is revealed in these parameters.

The loss in speed and, in turn, loss in horsepower were anticipated during the conceptual design study. Turbine cooling airflow is greater with water injection because the cooling air becomes denser as water is added. Thus more compressor air is diverted for turbine cooling, and less air is available to drive the turbine than with dry turbine cooling air. The result is a decrease in rotor speed. Another consideration was that the cooler turbine blades become shorter, thus increasing the tip clearance and causing a drop in turbine efficiency.

The speed decrease would be only one consequence of water injection if this were an operational system. The additional heat sink available in the turbine cooling air because of the water's latent heat of vaporization did lower the firststage turbine blade temperature ( $F$ ig. 8 ) even as rotor speed and horsepower decreased. The water addition permitted operation at a higher turbine rotor inlet temperature, as would be accomplished in a real-world contingency power situation by a throttle push, or fuel increase. 
The throttle push was done and the results for operation at or near IRP, the normal range where contingency power is applicable, are shown in

Fig. 9. These data were obtained by increasing the rotor speed after water addition until it was approximately equal to the speed before water addition. The result was a turbine blade leading-edge temperature approximately the same with and without water addition but with a higher power output than without water.

The power increase was approximately 3.5 percent for a 6 to 7 percent water addition (Fig. 9) and allowed a corresponding turbine rotor inlet temperature increase of about $60 \mathrm{deg} F$. This was in good agreement with the rate of power increase estimated by the conceptual design study. If the restraints previously mentioned for this testbed engine did not exist and it were possible to raise the turbine rotor inlet temperature by 300 deg $F$ as was done in the conceptual design study, a 17 percent increase in horsepower could be realized.

Data were not gathered at IRP, or above, beyond a 6 to 7 percent water/air ratio because, as is shown in $\mathrm{Fig} .8$, beyond that level there appeared to be little or no benefit from additional water injection. Simply, additional amounts of water beyond the 6 to 7 percent level did not significantly lower turbine blade leading-edge metal temperature. One explanation is that it could be a configuration-dependent mixing problem (i.e., type of distribution ring, number of holes in the ring, engine configuration, etc.).

Engine - Model Results

Engine and model test results disagreed in predicting the water/air ratio beyond which this configuration would show no increase in cooling capacity. This can be seen by comparing Figs. 5 and 8 , which show a marked change in slope (or a decrease in temperature) at different water/air ratios. This lends credence to the argument that the engine data are limited in water/air ratio effectiveness by configuration constraints rather than saturation conditions.

\section{Engine - Conceptual Design Results}

Comparing first-stage turbine blade leadingedge temperatures from the engine test results and the conceptual design study was difficult because the engine test was run at varying turbine inlet temperatures while the study was performed at a constant turbine inlet temperature. An attempt was made (Fig. 10) to compare the test and study results by using a dimensionless temperature parameter that contained key temperatures such turbine inlet temperature, coolant temperature, and turbine blade leading-edge temperature. The equation is

$$
T^{*}=\frac{T_{M}-T_{C}}{T_{G}-T_{C}}
$$

\section{where}

TC coolant temperature downstream of accelerator $T_{G}$ calculated turbine rotor inlet gas temperature $T_{M}$ first-stage turbine blade leading-edge temperature
Considering the limited amount of data avai1able and the limited range of conditions covered during the engine tests, the results are reasonable. The disagreement can be explained by the lack of instrumentation, because of space restrictions, needed for accurately determining the mixed air/steam temperature downstream of the accelerator.

\section{Concluding Remarks}

Because of one-engine-inoperative requirements, together with hot-gas reingestion and hotday, high-altitude takeoff situations, power augmentation for multiengine rotorcraft has always been of critical interest. However, power augmentation using overtemperature at the turbine inlet will shorten turbine 1 ife unless a method of limiting thermal and mechanical stresses is found. A possible solution involves allowing the turbine inlet temperature to rise to provide the augmented power while injecting water into the turbine cooling air to maintain hot-section metal temperatures. This solution was investigated as follows:

1. A unique system for injecting and evaporating water into the turbine cooling air was successfully designed, fabricated, installed, and tested in a T700 turboshaft engine.

2 . The results of the tests demonstrated the potential for increases in power of 17 percent, corresponding to increases in turbine inlet temperature of $300 \operatorname{deg} F$, while maintaining constant turbine rator blade temperature.

3. Concern for unprotected subcomponents in the hot section of the engine prevented demonstration of the technique's higher potential.

4. Further development of this unique system is required to optimize its potential for contingency power.

\section{References}

1. Dugas, R.E., "Gas Turbine Engine Power Augmentation and Emergency Rating, "USAAVLABSTR-68-12, 1968.

2. Vanfossen, G.J., "The Feasibility of Water Injection into the Turbine Coolant to Permit Gas Turbine Contingency Power for Helicopter Application," Journal of Engineering for Power, Vol. 105, No. 3, July 1983, pp. 635-642.

3. Richards, D.R., and Florschuetz, L.W., "Forced Convection Heat Transfer to Air/Water Vapor Mixtures," NASA CR-3769, 1984.

4. Janssen, J.M., Florschuetz, L.W., and Fiszdon, J.P., "Heat Transfer to Two-Phase Air/Water Mixtures Flowing in Small Tubes with Inlet disequilibrium," NASA CR-175076, 1986.

5. Hirschkron, R., Manning, R.F., and Haynes, J.F., "Contingency Power Study," R81AEG045, General Electric Co., Lynn, MA, Oct. 1981.

6. Hirschkron, R., Haynes, J.F., Goldstein, D.N., and Davis, R.H., "Rotorcraft Contingency Power Study," R84AEB012, General Electric Co., Lynn, MA, May 1984. (NASA CR-174675) 
TABLE I. - ENGINE SETTINGS FOR CONTINGENCY POWER INVESTIGATION USING WATER-AIR TURBINE COOLING

\begin{tabular}{|c|l|c|}
\hline Test & \multicolumn{1}{|c|}{ Identification } & $\begin{array}{c}\text { Water/air } \\
\text { ratio, } \\
\text { percent }\end{array}$ \\
\hline 1.0 & Shakedown & - \\
2.0 & Baseline data & ---- \\
3.0 & Shakedown of water injection system & --- \\
4.0 & Turbine inlet temperature < IRP: & 0 to 10 \\
4.1 & Base & 0 to 10 \\
4.2 & Base + 100 deg F & 0 to 10 \\
4.3 & Base + 135 deg F & 0 to 6 \\
5.0 & Turbine inlet temperature $\geq$ IRP: & 0 to 6 \\
5.1 & IRP & IRP+ \\
5.2 & IRP & \\
\hline
\end{tabular}




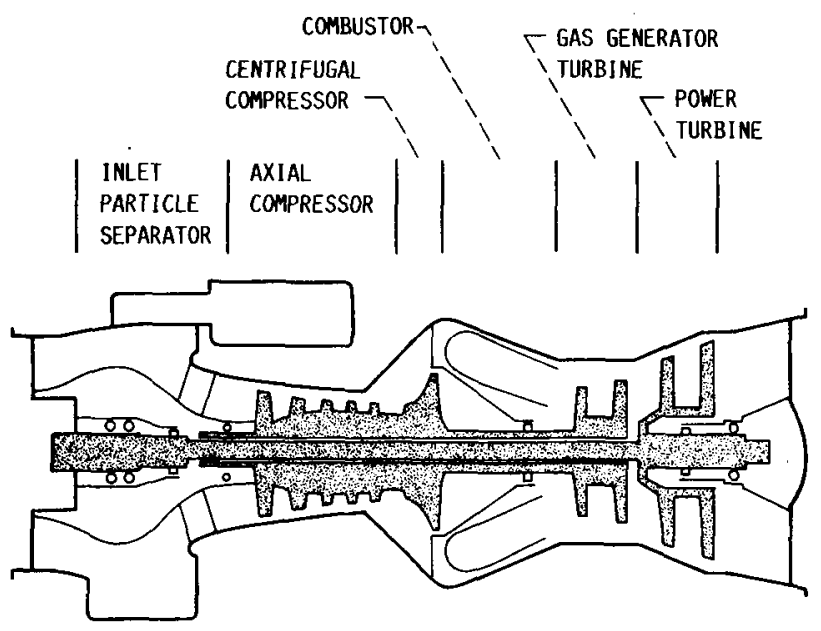

FIG. 1 SCHEMATIC OF ENGINE. 


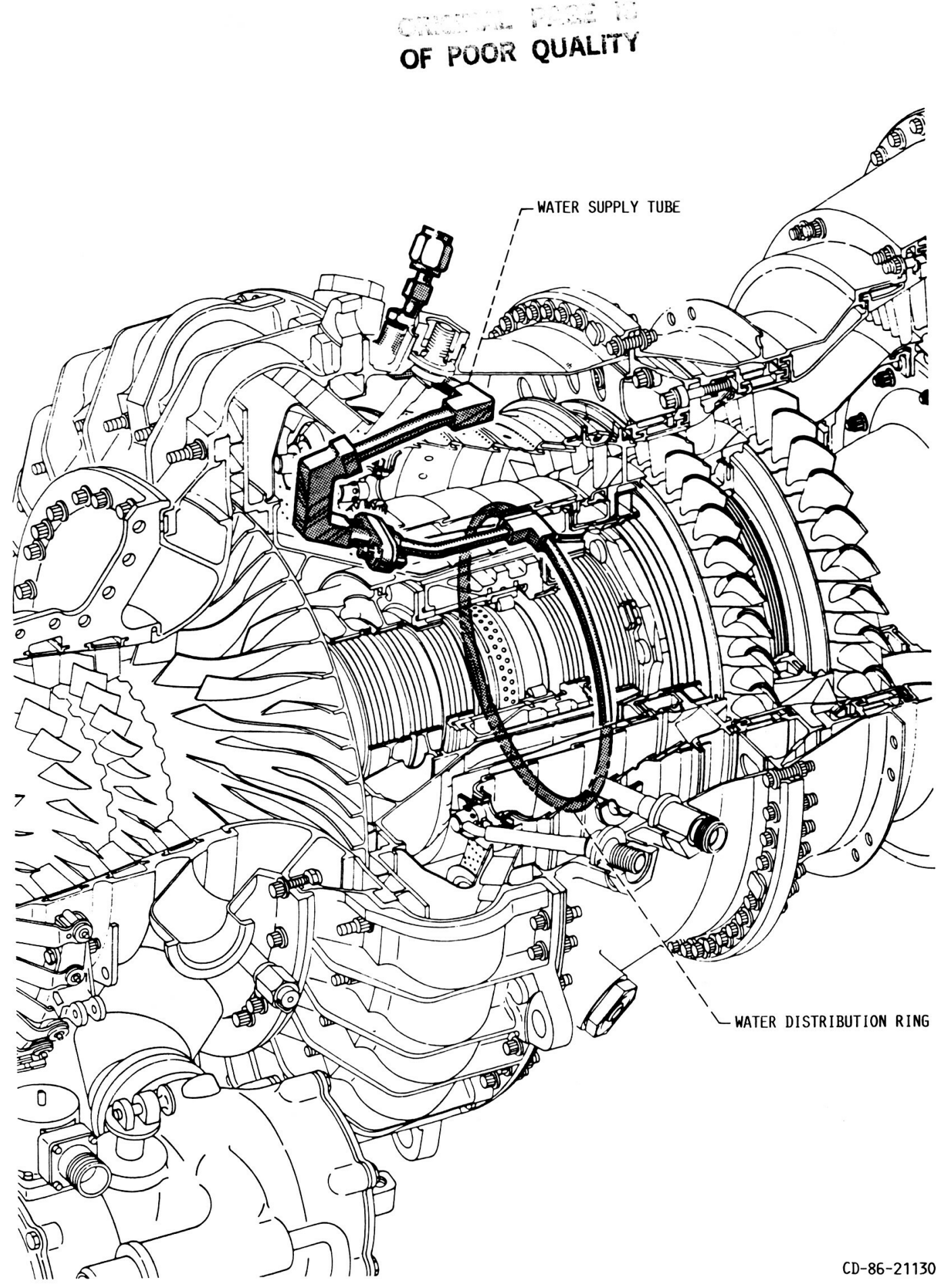

FIG. 2 WATER INJECTION SYSTEM INSTALLED IN ENGINE. 


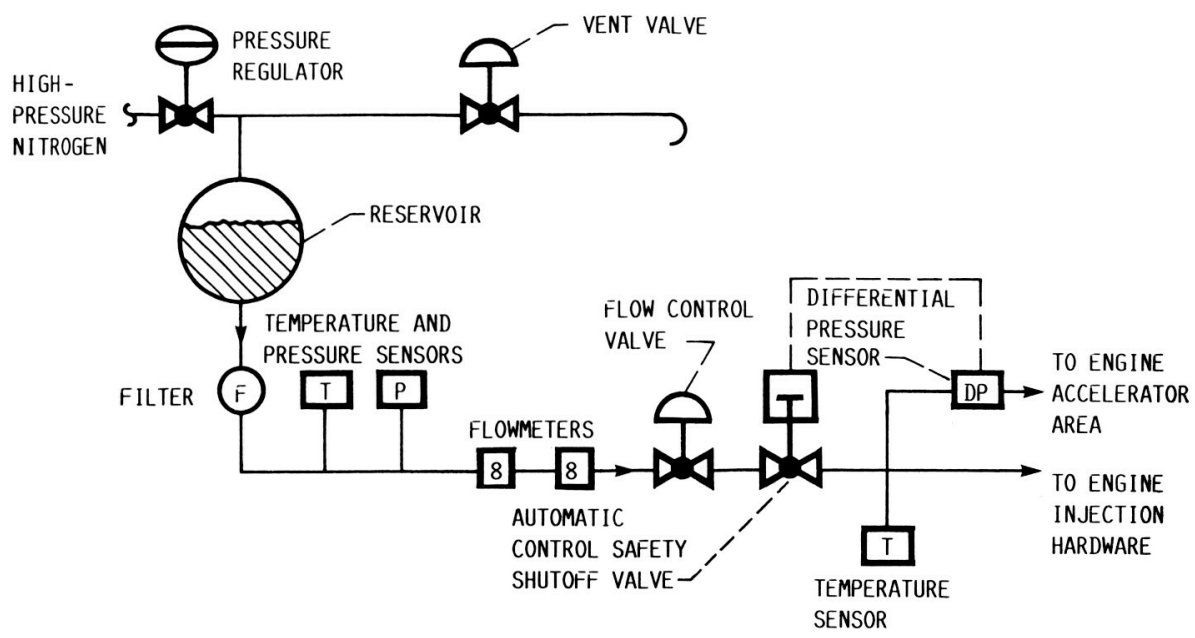

(A) SCHEMATIC OF OVERALL SYSTEM.

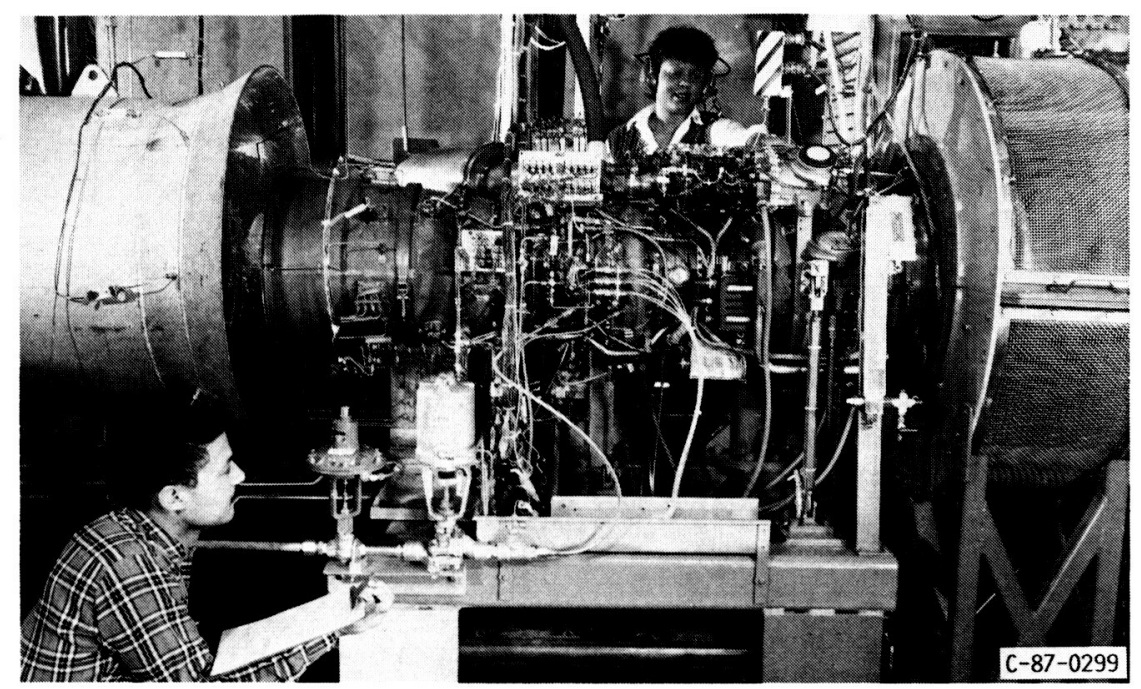

(B) TEST inStallation.

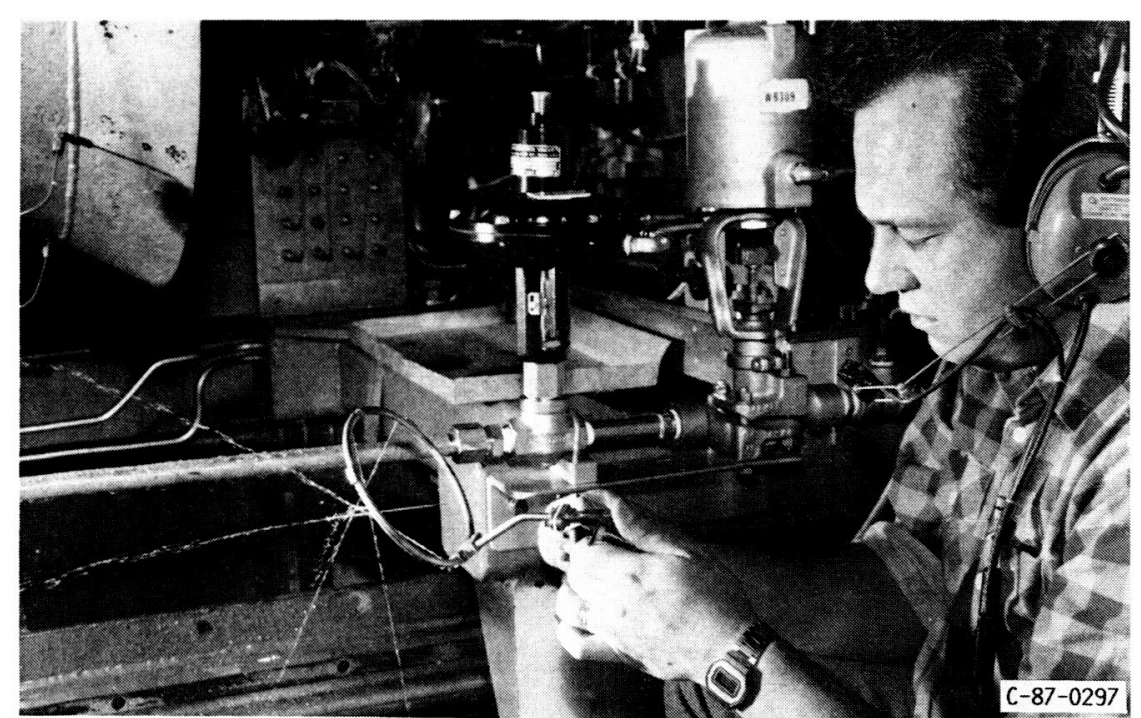

(C) SUPPLY TUBE AND DISTRIBUTION RING.

FIG. 3 WATER INJECTION SUPPLY SYSTEM. 


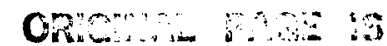

OF POOR OUALITY

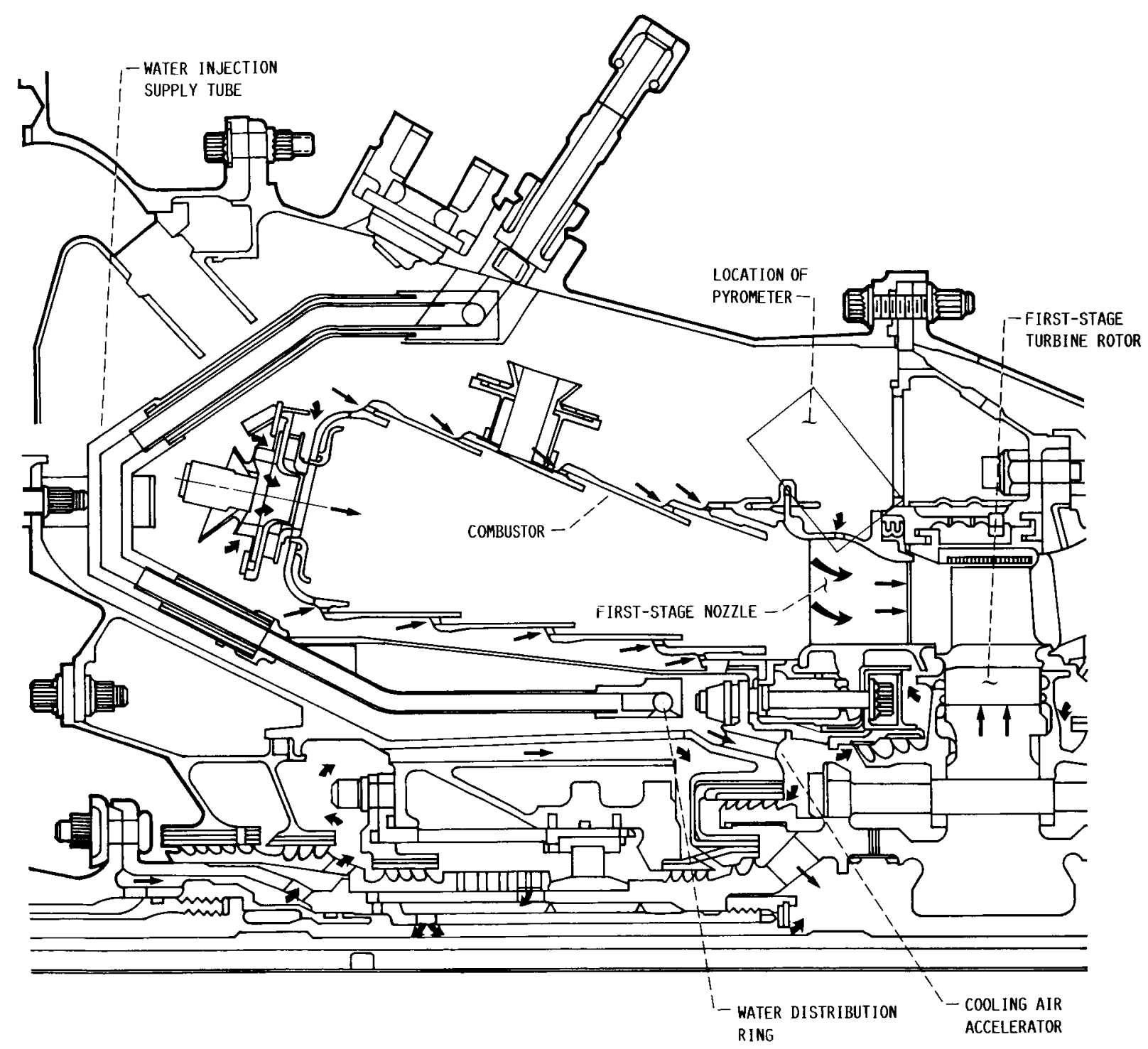

Fig. 4 LOCATION OF PYROMETER IN ENGINE hOT SECTION. 


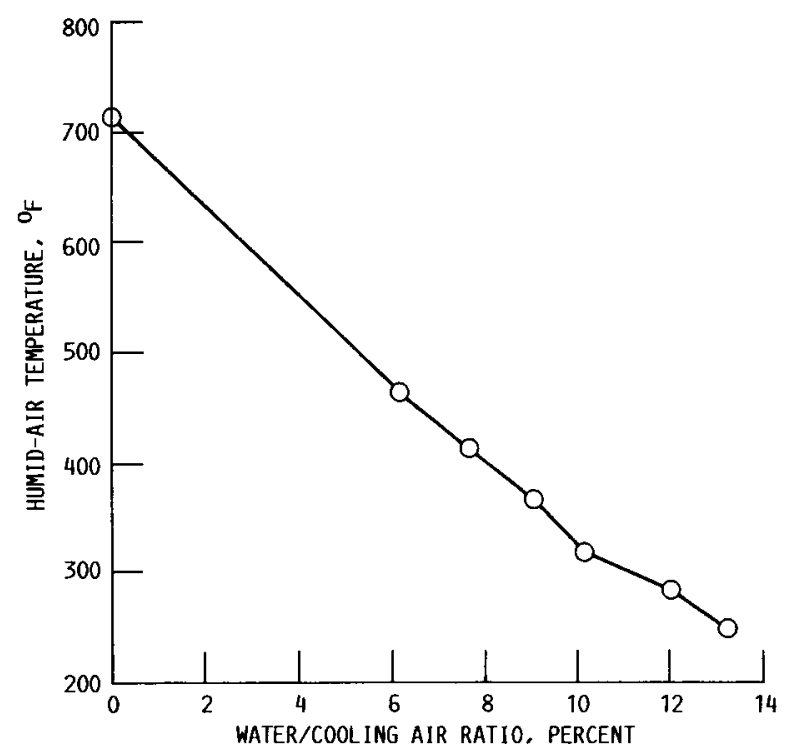

FIG. 5. - EFFECT OF WATER/COOLING AIR RATIO ON HUMIDAIR TEMPERATURE DOWNSTREAM OF ACCELERATOR. FIVE-HOLE DISTRIBUTION RING: AIRFLOW RATE, 0.46 LB/SEC.

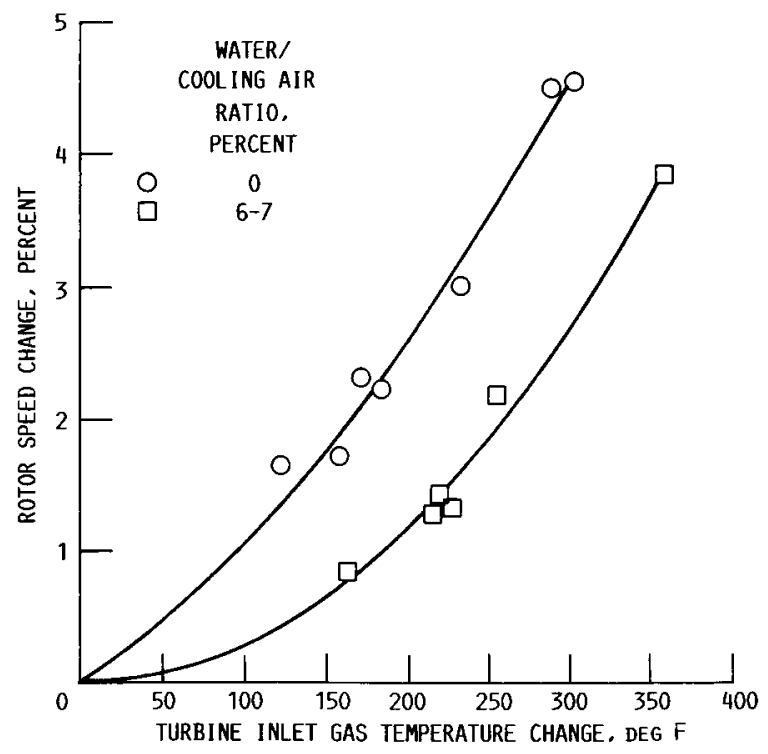

FIG. 6 EFFECT OF WATER ADDITION ON ROTOR SPEED AND TURBINE INLET TEMPERATURE (CHANGE FROM BASE CONDITION). 


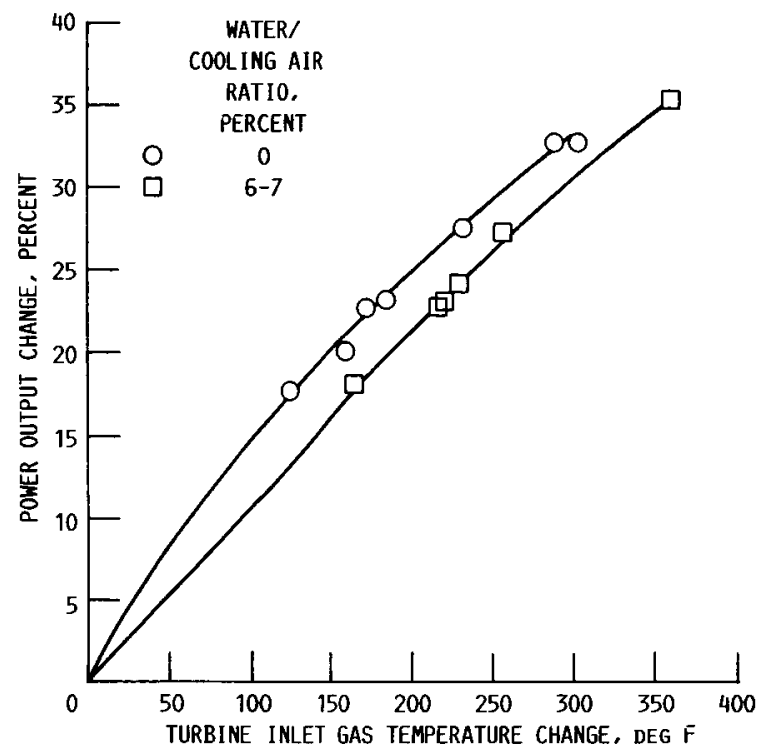

FIG. 7 EFFECT OF WATER ADDITION ON POWER OUTPUT AND TURBINE INLET TEMPERATURE (CHANGE FROM BASE CONDITION).

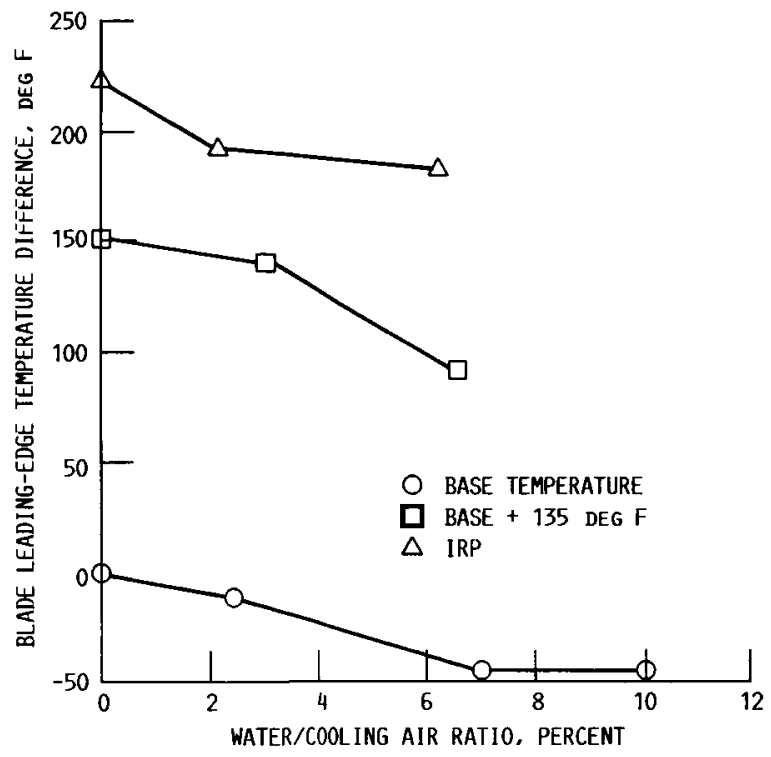

FIG. 8 EFFECT OF WATER/COOLING AIR RATIO ON FIRSTSTAGE TURBINE BLADE LEADING-EDGE TEMPERATURE. 


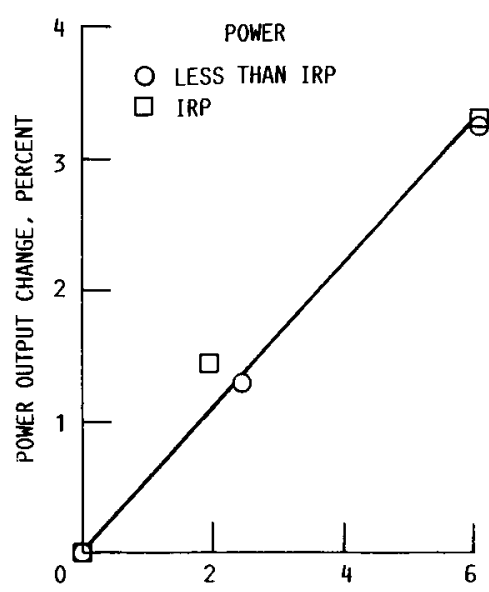

WATER/COOLING AIR RATIO, PERCENT

FIG. 9 EFFECT OF WATER/COOLING AIR RATIO ON POWER OUTPUT WITH FIRST-STAGE TURBINE BLADE LEADING EDGE TEMPERATURE CONSTANT.

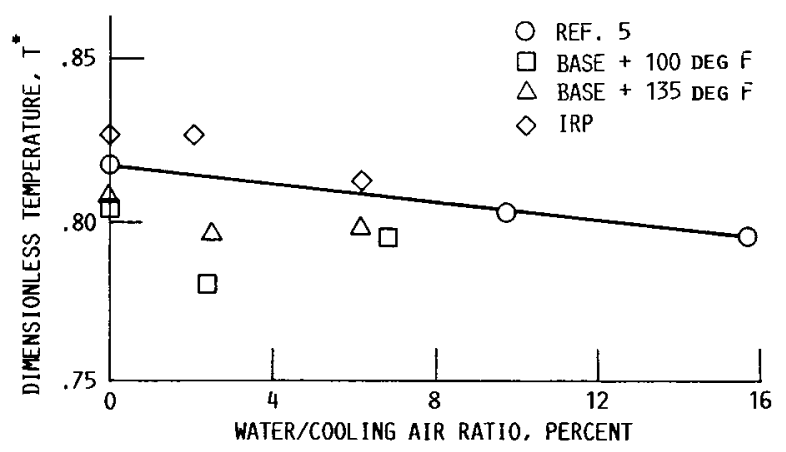

FIG. 10 EFFECT OF WATER/COOLING AIR RATIO ON DIMENSIONLESS TEMPERATURE. $T^{*}=\left(T_{M}-T_{C}\right) /\left(T_{G}-T_{C}\right)$. 


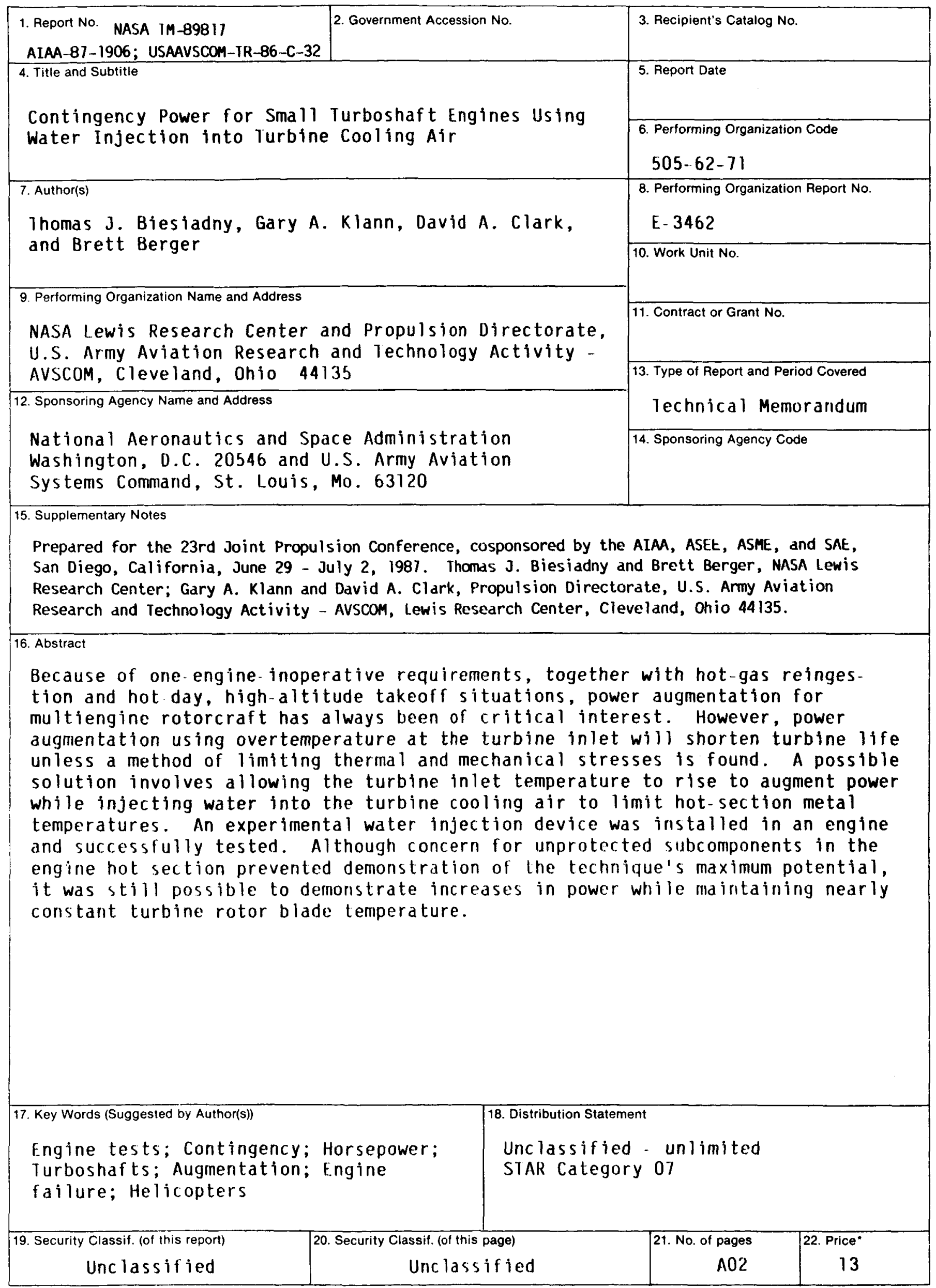

*For sale by the National Technical Information Service, Springfield, Virginia 22161 